facilitated this; for example, increased awareness of HIV/AIDS has in a small number of countries, such as Mexico, gradually removed the 'shroud of silence' (p. 153) from gay male culture. Nevertheless, at the same time states have resorted to new modes of repression even where homosexuality is not technically an offence, for instance by excluding openly gay politicians from government office.

Other sections of the book offer reviews of changing patterns of women's and men's engagement with the labour market and include a focus on gender differences in migration both nationally and internationally, providing clear and detailed analysis of current trends in the region. Female rates of participation in paid labour have increased across the region and the authors show how this situation has arisen following the introduction of neo-liberal economic reform programmes which have resulted in a proliferation of service industries across Latin American cities and have favoured women's employment. However, neoliberal reforms have also led to an overall deterioration in working conditions, which has overlain, and in some cases exacerbated, a variety of gender inequalities in the labour market. Gender gaps in wages remain high and women are more likely than men to be employed in low-paid, low-status occupations with little chance of improving their long-term situation.

The book concludes with a reflection on the gains made by Latin American feminist activists and women over the last decades and considers some future policy directions that are required to support these gains as well as some areas for future research. In particular, the study argues, if gender relations are to be effectively addressed men need to become more involved in the fight for change. Although this can bring problems to the struggle for change there are also many positive examples cited of women and men working together to challenge prevalent gender norms.

Overall, the book provides a thoughtful and fascinating starting point for those wanting to know more about questions of gender across the region. While it presents a reflection on gender relations in Latin America the analysis clearly offers useful lessons that extend beyond the confines of the region. It is written in a clear and accessible style that will appeal to 'specialists' and 'non-specialists' alike and is both informative and enjoyable to read.

doi:10.1057/palgrave.fr. 9400211

Jasmine Gideon

\title{
Gender's place. Feminist anthropologies of Latin America
}

Rosario Montoya, Lessie Jo Frazier and Janise Hurtig (editors); Palgrave, 2002, London; 304pp., ISBN: 1-4039-6040-2 (Pbk) £13.99

Gender's Place is an impressive edited collection of ethnographic case studies of gender in Latin America. While it is remarkably wide-ranging, both thematically 
and geographically, the volume as a whole manages to achieve coherence, which is to the editors' credit. Their introduction states the general aims of the book, emphasizing the importance of place and context in anthropological studies, and the role of scholarship as (potentially) feminist activism. They approach the latter through the concept of 'desalambrar', taken from a Uruguayan resistance song and meaning 'to tear down fences'. They have clearly asked their contributors to consider this concept explicitly, which works more or less successfully, depending on the case study. There are two broad approaches to 'desalambrar' among the contributors: those who study how women or men have 'torn down the fences', which assign them particular gender roles, and those who use their fieldwork to destabilize the boundaries that are part of academic research on gender.

This is not the most important contribution of this book, though, because its strength actually lies in the different case studies. They draw on material from Venezuela, Ecuador, Nicaragua, Chile, Mexico, Peru, Bolivia, the US/Mexico border and Brazil, and cover an equally wide range of themes. The first part is titled Gendered Knowledge in Particular Places, and discusses how Venezuelan teenagers approach a school debate on the situation of women in Venezuela (Janise Hurtig), the construction of masculinity in the Ecuadorian Andes (Barry Lyons) and the ways in which Nicaraguan women play with the categories of 'good' and 'bad' women to construct respectable lives for themselves (Montoya). Thematically, this part begins to bring in the issue of gendered agency, which is important throughout the collection.

The second part focuses on the role of the state, law and elites (including intellectuals and NGO activists) in contesting and reproducing gendered ideologies. Its emphasis moves from the state and law to the interactions of gender and ethnicity in the context of political action. It begins with Lessie Jo Frazier's chapter on a state-run mental health programme for the survivors of human rights violations in Chile. Ana María Alonso's very strong contribution then discusses the interplay of liberalism and changing gender constructions in 19thcentury Mexico, as visible in legislation on domestic violence. Marisol de la Cadena's contribution to this section is also historical, analysing how market women constructed their identities as 'cholas' in early 20 th-century Peru. Susan Paulson addresses questions of gender and ethnicity, over three 'sites' in Bolivia: feminist activists who went to work in state departments in the mid-1990s, the NGO-intellectual sphere of an irrigation project research seminar, and the experience of her informants. Her chapter and that of de la Cadena are both notable for the way in which they pay attention to ordinary people's own agency in the construction of their identities, as do Lyons and Montoya from the previous section.

The third section's slightly forced title, Gender in Movement(s), picks up on the theme of social movements introduced in the second part: from indigenous women 
leaders in Ecuador (Emma Cervone) to politically active travestis in Porto Alegre, Brazil (Charles Klein). Victor Ortiz's chapter describes the movement of jobs, skills and entrepreneurship between Texas and Northern Mexico in the context of NAFTA. Both he and Cervone use the stories of two individual women to illustrate their main points. Marta Lamas' contribution is the last of the case studies, and is a fascinating account of how prostitutes in Mexico City use ritual to build their identity as a collective group, and to appropriate a space for themselves. Klein's article shares the focus on sex-workers. Both analyse the subversive use of space, as people who are usually out at night time appropriate the street for themselves. In Klein's case, this was in order to demonstrate against the violence the travestis frequently suffer, by 'making a scene' in the middle of the day and the middle of the city. As with the previous sections, the emphasis on agency is central.

Throughout the volume, the focus on gendered agency, subversion, transgression and resistance is not romanticized. Indeed, another theme is the ways in which women and men reinforce gendered expectations and categories as well as 'tearing down the fences' between them. It has to be said, though, that the fourth section, Critical Commentaries, did not fully take advantage of the incredibly rich material in the preceding 11 case studies, despite participation from some highly respected Latin American and Latin Americanist feminists. Marysa Navarro's contribution is an absolutely blistering critique of 'marianismo', and very useful as such. The term 'marianismo' was coined by Evelyn Stevens in 1973 and describes an ideology of female spiritual and moral superiority over men, drawing on the veneration of the Virgin Mary, and being the opposite of machismo. However, since none of the other contributors to the volume even obliquely refer to 'marianismo', the chapter feels slightly out of place. The rest of the fourth section, with contributions from Sonia Montecino, Altha Cravey and June Nash also feels 'tacked on'. While I had overcome an initial mistrust of the concept of 'desalambrar' through reading the case studies, this section made me question it again, and I almost became resentful at being told what to think about the collection. I started to wonder about the need to 'desalambrar' the fence between author and reader, and to trust the readers to make up their own minds.

However, the strength of the ethnographic chapters more than compensates for any problems with the final, short section. The chapters are so rich thematically that it would probably be difficult to do them full justice in any theoretical contribution. I read the collection from beginning to end, and felt that it worked, but one could just as easily pick out individual chapters. On the whole, this volume reinvigorated my enthusiasm for gender in Latin America, as well as moving forward theoretically. It should be of interest to anyone working on anthropology and/or gender in Latin America.

Sian Lazar

doi: 10.1057/palgrave.fr. 9400210 